\title{
Maternal and infant correlates of maternal feeding beliefs and practices in a multi-ethnic Asian population: the GUSTO (Growing Up in Singapore Towards healthy Outcomes) study
}

\author{
Phaik Ling Quah ${ }^{1}$, Tuck Seng Cheng ${ }^{2}$, Yin Bun Cheung ${ }^{3,4}$, Fabian Yap ${ }^{2,5}$, \\ Seang-Mei Saw ${ }^{6}$, Keith M Godfrey 7,8 , Peter D Gluckman ${ }^{1,9}$, Yap-Seng Chong ${ }^{1,10}$ and \\ Mary Foong-Fong Chong ${ }^{1,11,12, *}$ on behalf of the GUSTO Study Group \\ ${ }^{1}$ Singapore Institute for Clinical Sciences, Agency for Science, Technology and Research, Brenner Centre for \\ Molecular Medicine, 30 Medical Drive, Singapore 117609: ${ }^{2}$ Department of Paediatrics, KK Women's and \\ Children's Hospital, Singapore: ${ }^{3}$ Center for Quantitative Medicine, Duke-NUS Graduate Medical School, \\ Singapore: ${ }^{4}$ Department for International Health, University of Tampere, Tampere, Finland: ${ }^{5}$ Duke-NUS Graduate \\ Medical School, Singapore: 'Saw Swee Hock School of Public Health, National University of Singapore, Singapore: \\ ${ }^{7}$ MRC Lifecourse Epidemiology Unit, University of Southampton, Southampton, UK: ${ }^{8}$ NIHR Southampton Biomedical \\ Research Centre, University of Southampton and University Hospital Southampton NHS Foundation Trust, \\ Southampton, UK: ${ }^{9}$ Liggins Institute, University of Auckland, Auckland, New Zealand: ${ }^{10}$ Department of Obstetrics \& \\ Gynaecology, Yong Loo Lin School of Medicine, National University of Singapore, Singapore: ${ }^{1}$ Department of \\ Paediatrics, Yong Loo Lin School of Medicine, National University of Singapore and National University Health \\ System, Singapore: ${ }^{12}$ Clinical Nutrition Research Center, Singapore Institute for Clinical Sciences (SICS), Agency for \\ Science, Technology and Research (A*STAR), Singapore
}

Submitted 20 November 2015: Final revision received 1 March 2016: Accepted 8 March 2016: First published online 28 April 2016

\begin{abstract}
Objective: Little is known about the influences of maternal and infant correlates on maternal feeding beliefs and practices in the first 2 years of life, despite its important role in early obesogenic eating behaviours and weight gain.

Design: Cross-sectional study using demographic data of mothers and infants obtained at 26-28 weeks of gestation, and postnatally from birth to 15 months, respectively. The Infant Feeding Questionnaire was administered at 15 months postpartum. The associations between maternal and infant characteristics with seven maternal feeding beliefs and practices subscales were evaluated using multivariate linear regression analysis.

Setting: Data obtained from the Singapore GUSTO (Growing Up in Singapore Towards healthy Outcomes) mother-offspring birth cohort.

Subjects: Mothers and infants ( $n$ 1237).

Results: Among other maternal correlates such as age, education, BMI, income and milk feeding practices, ethnicity was a consistent factor associated with six subscales, including concern about infant overeating/undereating and weight status, concern and awareness about infants' hunger and satiety cues, social interaction during feeding and feeding an infant on schedule. Similarly, among infant correlates such as gender and birth order, infant body size gain (reflected by BMI $Z$-score change from 0 to 15 months) was significantly associated with all subscales except feeding an infant on schedule. Overall, maternal correlates had greater influence on all subscales compared with infant correlates except for the maternal concern about infant undereating or becoming underweight subscale.

Conclusions: The present study highlights that maternal feeding beliefs and practices can be influenced by both maternal correlates and infant correlates at 15 months of age.
\end{abstract}

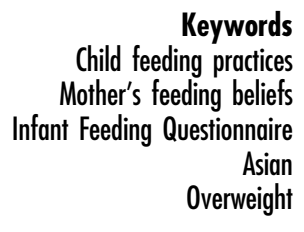

Mothers are primary caregivers responsible for shaping the eating environment of their children and fostering the development of healthy weight ${ }^{(1)}$. Maternal feeding beliefs and practices are known to have important influences on 
A recent review by McPhie et al. examining maternal correlates uncovered major determinants of maternal feeding beliefs and practices ${ }^{(7)}$. Lower maternal education level was related to increased use of food as a reward ${ }^{(8)}$ and reduced concern about a child's weight ${ }^{(9)}$. The influence of cross-cultural differences were noted when African-American and Spanish-speaking Hispanic compared with English-speaking Hispanics mothers ${ }^{(8)}$, as well as American compared with French mothers ${ }^{(10)}$, were significantly associated with the use of food to calm fussy infants or as a reward. In addition, mothers with higher BMI have been associated with poorer child eating habits ${ }^{(8)}$, reduced pressure and restrictions to eat in children $^{(11)}$, while other studies found no significant associations $^{(7,12,13)}$. In multi-ethnic studies conducted in the USA in children aged 2 to 7 years, both Hispanic and African-American parents preferred their children to be heavier $^{(14,15)}$, and tended to associate higher child BMI with health and strength ${ }^{(15,16)}$, compared with Whites.

While there is clear evidence emerging mostly from studies conducted in the USA and Europe, little is known about how these associations may be different in a multi-ethnic Asian population. So far, only one study conducted in the USA has shown that Asians' feeding practices differ from those of other ethnicities (Whites, Blacks and Hispanics) ${ }^{(17)}$, suggesting that maternal correlates of feeding practices from previous studies cannot be generalized to populations with diverse ethnic backgrounds.

There is also some evidence suggesting that child characteristics, such as weight ${ }^{(18,19)}$ and eating behaviour ${ }^{(3)}$, influence maternal restrictive ${ }^{(3,18,19)}$ and maternal pressuring $^{(3,19)}$ feeding practices, while gender influences maternal controlling feeding practices ${ }^{(12)}$. Other child characteristics including infant temperament have also been shown to influence maternal feeding practices such as the timing of solid food introduction ${ }^{(20)}$ and awareness of infant feeding cues ${ }^{(20)}$. Few studies have examined both maternal and infant characteristics in relation to feeding practices, so the relative contribution of maternal and infant correlates to maternal feeding beliefs and practices still remains unclear.

Factors influencing maternal feeding beliefs and practices at early time points are still largely unexplored. Most of the previously published studies ${ }^{(7-10,12,18,19,21)}$ have included only children above 3 years of age and used the Child Feeding Questionnaire (CFQ) by Birch et al., which was developed for children aged 3 to 11 years ${ }^{(22)}$. The Infant Feeding Questionnaire (IFQ) was designed to capture maternal feeding practices and beliefs predictive of early childhood obesity in children below 2 years of age $^{(23)}$. To our knowledge, only two studies have been conducted in early infancy (below 2 years of age) using the $\operatorname{IFQ}^{(23,24)}$.

In the present study we aimed to explore key maternal and infant correlates influencing maternal feeding beliefs and practices, which were assessed using the seven subscales of the IFQ at 15 months of age in a multi-ethnic Asian birth cohort in Singapore.

\section{Methods}

\section{Study design}

Data were obtained from the GUSTO (Growing Up in Singapore Towards healthy Outcomes) study, a population-based prospective mother-offspring cohort study in Singapore. Further details on the GUSTO study have been described previously by Soh et al. ${ }^{(25)}$. Pregnant women within the age range of $18-50$ years were recruited from the two major public maternity units in the National University Hospital and KK Women's and Children's Hospital. Participants had to be Singaporean citizens or permanent residents, of Chinese, Malay or Indian ethnicity with parents of homogeneous ethnic background. Written informed consent was collected from all participants upon recruitment. The study was granted ethical approval by the Institutional Review Boards of the respective hospitals involved (clinical trials registry: NCT01174875).

\section{Measures}

\section{Maternal and infant characteristics}

Demographic data on maternal age, educational level, household monthly income and marital status were collected from the women using interviewer-administered questionnaires at the recruitment visit and at 15-28 weeks of gestation. Information on infant gender and birth order were obtained from birth delivery reports. After delivery, infant feeding modes in the first 6 months of life (exclusively breast-feeding, partially breast-feeding, exclusively formula-feeding) ${ }^{(26)}$ were reported by parents.

\section{Anthropometric measurements}

Infant anthropometric measurements were taken by trained clinical staff at birth (within $24 \mathrm{~h}$ ) and 15 months of age. Weight was recorded to the nearest $0.001 \mathrm{~kg}$ using SECA 334 baby weighing scales (Hamburg, Germany). Recumbent crown-heel length was measured to the nearest $0 \cdot 1 \mathrm{~cm}$ using a SECA 210 Mobile Measuring Mat. Based on the WHO Child Growth Standards 2006, infant weight and length were converted to BMI $Z$-scores and weight-for-length Z-scores using WHO Anthro software (version 3.2.2). Body size changes at 0-15 months were calculated by subtracting BMI $Z$-scores at birth from BMI $Z$-scores at 15 months of age. Similar calculations were applied for weight-for-length $Z$-score change at 0-15 months. The BMI and weight-for-length $Z$-score changes at 0-15 months were strongly correlated $(r=0 \cdot 92)$. BMI $Z$-scores were used for further analysis as these scores are adjusted for age and gender, providing a more accurate estimate of body fatness. Mothers' self-reported pre-pregnancy weight and weight in early pregnancy $(<15$ weeks of 
gestation) were collected from hospital case notes, while height was measured at 26-28 weeks of gestation using a SECA 206 stadiometer. BMI was calculated as weight in kilograms divided by the square of height in metres. Mothers' BMI in early pregnancy strongly correlated with mother's pre-pregnancy BMI $(r=0.96)$ and was used for further analyses because it had a lower percentage of missing data ( $n$ 41, 4.4\%).

\section{Infant Feeding Questionnaire}

The English version of the IFQ ${ }^{(23)}$ was self-administered by mothers to assess the maternal feeding beliefs and practices at the 15-month time point. It is a twenty-eightitem questionnaire that was answered using a 5-point Likert scale-type format ranging from 'never' to 'always' or from 'disagree a lot' to 'agree a lot'. The original IFQ conducted exploratory factor analysis which produced twenty items classified into seven subscales including: (i) Concern about child undereating or becoming underweight (items 2, 8, 18 and 24); (ii) Concern about infant's hunger (items 13, 15 and 16); (iii) Awareness of infant's hunger and satiety cues (items 20, 25, 26 and 28); (iv) Concern about infant overeating or becoming overweight (items 7, 9 and 27); (v) Feeding infant on schedule (items 1 and 3); (vi) Using food to calm infant's fussiness (items 6 and 19); and (vii) Social interaction with infant during feeding (items 11 and 14; see online supplementary material, Supplemental Table 1).

\section{Statistical analysis}

\section{Confirmation factor analysis}

In the present study, confirmatory factor analysis was performed to determine the fit of the original seven-factor structure by Baughcum et al. ${ }^{\text {(23) }}$ to our current data. It was shown that the seven-factor model provided a moderately good fit to our data (root-mean-square error of approximation $($ RMSEA $)=0 \cdot 051$, comparative fit index $(\mathrm{CFI})=$ $0 \cdot 873)^{(27-29)}$. Since item 15 appeared to have a weak factor loading, and in the opposite direction to other items $(-0 \cdot 16)$ in the same factor (Concern about infant's hunger), a second confirmatory factor analysis which excluded question 15 was performed. This modified model provided a better fit to our data (RMSEA $=0.049, \mathrm{CFI}=$ $0 \cdot 897)^{(27-29)}$. Hence, the original classification of the items in the IFQ was adopted except for the Concern about infant's hunger factor from which item 15 was excluded. Methods for calculating scale scores and handling missing items for each factor were the same as in the guidelines given by Baughcum et al. ${ }^{(23)}$. In brief, the subscale score is the simple average of the item scores. A missing item could be replaced with the mean score of the other items for four-item factors only if at least three of the four items were answered. A subscale score was considered missing for a respondent if at least one item was missing from the two- or three-item factors.

\section{Univariate and multivariate analyses}

The independent two-sample $t$ test for continuous variables and Fisher's exact test for categorical variables were computed to compare the differences in maternal and infant characteristics between responders and nonresponders to the IFQ. Multivariable linear regression analyses were performed to analyse the association of maternal and infant characteristics with the subscale scores of the seven-factor structure of the IFQ. Two multivariate models were conducted and variables were selected on the basis of a priori hypotheses. The first model only included maternal characteristics as one block, such as maternal age, ethnicity, education, household monthly income, milk feeding practices in the first 6 months of life and BMI in early pregnancy; the second model included the aforementioned maternal characteristics and another block of infant characteristics which were infant gender, birth order and BMI $Z$-score change between 0 and 15 months. The maternal characteristics block was first entered followed by the infant characteristics block into the regression model. All variables are mutually adjusted in the same model. The relative contribution of each block of independent variables (maternal characteristics and infant characteristics) to the variation in scores for each subscale was estimated by the $R^{2}$ change in each model. Relative contribution of maternal correlates was computed as $R^{2}$ in model 1 , while the relative contribution of infant correlates was calculated by subtracting $R^{2}$ of model 1 from $R^{2}$ of model 2 . This method of evaluating $R^{2}$ change has been used in previous studies $^{(30,31)}$.

Statistical significance was identified by a $P$ value of $<0.05$. All statistical analyses were performed using the statistical software package Stata version 13.1.

\section{Results}

\section{Characteristics of participants}

Out of 1247 women recruited ${ }^{(25)}$, ten multiplets were excluded from our analysis. Of the 1237 mothers of singletons, $75.6 \%$ ( $n$ 935) responded to the IFQ.

The maternal and infant characteristics of the responders and non-responders to the questionnaire are summarized in Table 1. A higher percentage of the responders compared with the non-responders were Chinese $(P=0.004)$ and married $(P=0.030)$, had tertiary education $(P<0.001)$ and had an average household monthly income $\geq$ SGD6000 $(P=0.007$; where SGD $=$ Singapore dollars). The responders were also older $(P=0.001)$, with a mean age of 30.96 years. In relation to the infant characteristics, there was a higher percentage of term birth infants $(P=0 \cdot 013)$ and of heavier infants $(P<0.001)$ with a mean birth weight of $3.12 \mathrm{~kg}$ in the responders group (Table 1 ). 
Table 1 Population characteristics of non-responders and responders to the Infant Feeding Questionnaire; GUSTO (Growing Up in Singapore Towards healthy Outcomes) mother-offspring birth cohort, Singapore

\begin{tabular}{|c|c|c|c|c|c|}
\hline & \multicolumn{2}{|c|}{ Non-responders ( $n$ 302) } & \multicolumn{2}{|c|}{ Responders ( $n$ 935) } & \multirow[b]{2}{*}{$P$ value } \\
\hline & $n$ or Mean & $\%$ or SD & $n$ or Mean & $\%$ or SD & \\
\hline \multicolumn{6}{|l|}{ Maternal characteristics } \\
\hline Ethnicity & & & & & 0.004 \\
\hline Chinese & 146 & $48 \cdot 3$ & 545 & $58 \cdot 3$ & \\
\hline Malay & 99 & $32 \cdot 8$ & 224 & $24 \cdot 0$ & \\
\hline Indian & 57 & $18 \cdot 9$ & 166 & $17 \cdot 8$ & \\
\hline Education & & & & & $<0.001$ \\
\hline None/primary/secondary & 113 & $38 \cdot 6$ & 268 & $28 \cdot 9$ & \\
\hline Post-secondary & 108 & 36.9 & 322 & 34.7 & \\
\hline Tertiary & 72 & $24 \cdot 6$ & 337 & 36.4 & \\
\hline Household income & & & & & 0.007 \\
\hline SGD0-1999 & 48 & $17 \cdot 6$ & 133 & $15 \cdot 1$ & \\
\hline SGD2000-5999 & 166 & $61 \cdot 0$ & 474 & 53.9 & \\
\hline$\geq$ SGD 6000 & 58 & $21 \cdot 3$ & 273 & 31.0 & \\
\hline Milk feeding practices up to 6 months & & & & & 0.232 \\
\hline Fully breast-fed & 10 & 7.5 & 103 & 11.4 & \\
\hline Partially breast-fed & 99 & 73.9 & 670 & $74 \cdot 0$ & \\
\hline Fully formula-fed & 25 & $18 \cdot 7$ & 132 & $14 \cdot 6$ & \\
\hline Marital status & & & & & 0.030 \\
\hline Single/divorced & 17 & $5 \cdot 8$ & 27 & $2 \cdot 9$ & \\
\hline Married & 275 & $94 \cdot 2$ & 892 & $97 \cdot 1$ & \\
\hline Age (years) & 29.39 & $5 \cdot 22$ & 30.96 & 5.09 & 0.001 \\
\hline Pregnancy BMI at $<15$ weeks $\left(\mathrm{kg} / \mathrm{m}^{2}\right)$ & 23.92 & 5.04 & 23.66 & 4.71 & 0.470 \\
\hline \multicolumn{6}{|l|}{ Infant characteristics } \\
\hline Gender & & & & & 0.827 \\
\hline Male & 126 & 53.6 & 492 & $52 \cdot 6$ & \\
\hline Female & 109 & $46 \cdot 4$ & 443 & $47 \cdot 4$ & \\
\hline Birth order & & & & & 0.213 \\
\hline First child & 116 & 49.4 & 417 & $44 \cdot 6$ & \\
\hline Not first child & 119 & $50 \cdot 6$ & 518 & 55.4 & \\
\hline Type of birth & & & & & 0.013 \\
\hline Preterm & 28 & 11.9 & 63 & $6 \cdot 7$ & \\
\hline Term & 207 & $88 \cdot 1$ & 872 & 93.3 & \\
\hline Type of conception & & & & & 0.516 \\
\hline Natural & 284 & $94 \cdot 0$ & 868 & $92 \cdot 8$ & \\
\hline IVF & 18 & $6 \cdot 0$ & 67 & $7 \cdot 2$ & \\
\hline Birth weight $(\mathrm{kg})$ & 2.96 & 0.49 & 3.12 & 0.43 & $<0.001$ \\
\hline BMI Z-score change at $0-15$ months & 0.32 & $1 \cdot 27$ & 0.17 & $1 \cdot 31$ & 0.530 \\
\hline
\end{tabular}

SGD, Singapore dollars; IVF, in vitro fertilization.

Data are presented as $n$ and \% for categorical variables, or as mean and SD for continuous variables (maternal age and BMI in early pregnancy; infant birth weight and BMI Z-score change).

\section{Concern about infant undereating or becoming underweight}

Table 2 shows the association of maternal and infant characteristics with concern about infant under- or overeating and infant's weight status. Compared with the Chinese mothers, the Malay $(P=0.006)$ and Indian mothers $(P<0.001)$ were more concerned about their infants undereating or becoming underweight. This association remained significant after adjustment for both infant and maternal characteristics (model 2; $P=0.001$ and $P<0.001$, respectively). Several infant characteristics were associated with this subscale when adjusted for both infant and maternal characteristics (model 2). Mothers of infants who were first born $(P=0.001)$, female $(P=0.025)$ and with lower BMI $Z$-score change between 0 and 15 months $(P=0.001)$ were more concerned about their infants undereating or becoming underweight (Table 2). For this subscale, the infant correlates influenced the scores more than maternal correlates ( $R^{2}$ change: $5.6 \% v .4 .0 \%$ ).

\section{Concern about infant overeating or becoming being overweight}

Similarly, ethnicity was the only maternal characteristic associated with mothers' concern about their infants overeating or becoming overweight. Compared with the Chinese, Malay mothers showed more concern about their infants overeating or becoming overweight $(P=0 \cdot 021)$, while Indian mothers showed less concern $(P<0 \cdot 001$; model 2, Table 2). However, in contrast to the previous subscale, mothers of infants with higher BMI Z-score change between 0 and 15 months were more concerned about the infant overeating or becoming overweight $(P=0.003$; model 2 , Table 2). Maternal characteristics influenced the scores of this subscale more than infant characteristics ( $R^{2}$ change: $\left.6.3 \% v .1 .3 \%\right)$. 
Table 2 Maternal and infant characteristics associated with maternal concern about infant undereating/becoming underweight and overeating/becoming overweight; GUSTO (Growing Up in Singapore Towards healthy Outcomes) mother-offspring birth cohort, Singapore

\begin{tabular}{|c|c|c|c|c|c|c|c|c|c|c|c|c|}
\hline & \multicolumn{6}{|c|}{$\begin{array}{c}\text { Subscale: Concern about infant undereating or becoming } \\
\text { underweight }(n 800)\end{array}$} & \multicolumn{6}{|c|}{$\begin{array}{l}\text { Subscale: Concern about infant overeating or } \\
\text { becoming overweight }(n 782)\end{array}$} \\
\hline & & Model 1 & $P$ value & & Model 2 & $P$ value & & Model 1 & $P$ value & & Model 2 & $P$ value \\
\hline \multicolumn{13}{|l|}{ Maternal characteristics } \\
\hline \multicolumn{13}{|l|}{ Ethnicity } \\
\hline Chinese & \multicolumn{2}{|c|}{ Reference } & \multicolumn{4}{|c|}{ Reference } & \multicolumn{2}{|r|}{ Reference } & \multicolumn{4}{|c|}{ Reference } \\
\hline Malay & 0.242 & $0.068,0.416$ & 0.006 & 0.297 & $0.127,0.467$ & 0.001 & 0.187 & $0.039,0.334$ & 0.013 & 0.174 & $0.027,0.321$ & 0.021 \\
\hline Indian & 0.345 & $0.162,0.528$ & $<0.001$ & 0.419 & $0.239,0.598$ & $<0.001$ & -0.340 & $-0.494,-0.186$ & $<0.001$ & -0.345 & $-0.500,-0.190$ & $<0.001$ \\
\hline \multicolumn{13}{|l|}{ Education } \\
\hline None/primary/secondary & \multicolumn{2}{|c|}{ Reference } & \multicolumn{4}{|c|}{ Reference } & \multicolumn{2}{|r|}{ Reference } & \multicolumn{4}{|c|}{ Reference } \\
\hline Post-secondary & -0.073 & $-0.237,0.091$ & 0.384 & -0.078 & $-0.240,0.084$ & 0.343 & -0.029 & $-0.169,0.111$ & 0.683 & -0.055 & $-0.196,0.086$ & 0.443 \\
\hline Tertiary & 0.109 & $-0.088,0.306$ & 0.278 & 0.075 & $-0.121,0.270$ & 0.454 & -0.092 & $-0.259,0.076$ & 0.283 & -0.121 & $-0.291,0.049$ & 0.163 \\
\hline \multicolumn{13}{|l|}{ Household income } \\
\hline SGD0-1999 & \multicolumn{2}{|c|}{ Reference } & \multicolumn{4}{|c|}{ Reference } & \multicolumn{2}{|r|}{ Reference } & \multicolumn{4}{|c|}{ Reference } \\
\hline SGD2000-5999 & -0.004 & $-0.198,0.190$ & 0.966 & 0.020 & $-0.169,0.209$ & 0.837 & -0.087 & $-0.252,0.078$ & 0.302 & -0.104 & $-0.269,0.060$ & 0.214 \\
\hline$\geq$ SGD6000 & -0.215 & $-0.458,0.029$ & 0.084 & -0.186 & $-0.423,0.052$ & 0.125 & -0.068 & $-0.273,0.138$ & 0.518 & -0.085 & $-0.290,0.120$ & 0.417 \\
\hline \multicolumn{13}{|c|}{ Milk feeding practices up to 6 months } \\
\hline Fully breast-fed & \multicolumn{2}{|c|}{ Reference } & \multicolumn{4}{|c|}{ Reference } & \multicolumn{2}{|r|}{ Reference } & \multicolumn{4}{|c|}{ Reference } \\
\hline Partially breast-fed & -0.129 & $-0.332,0.074$ & 0.214 & -0.173 & $-0.371,0.026$ & 0.088 & -0.120 & $-0.290,0.051$ & 0.169 & -0.113 & $-0.284,0.057$ & 0.192 \\
\hline Fully formula-fed & -0.163 & $-0.432,0.107$ & 0.236 & -0.186 & $-0.449,0.076$ & $0 \cdot 164$ & -0.084 & $-0.311,0.143$ & 0.467 & -0.089 & $-0.315,0.136$ & 0.438 \\
\hline Age (years) & 0.004 & $-0.009,0.017$ & 0.545 & 0.011 & $-0.002,0.025$ & 0.103 & 0.003 & $-0.008,0.014$ & 0.604 & 0.005 & $-0.007,0.016$ & 0.437 \\
\hline Pregnancy BMI at $<15$ weeks $\left(\mathrm{kg} / \mathrm{m}^{2}\right)$ & -0.002 & $-0.016,0.013$ & 0.827 & -0.003 & $-0.017,0.011$ & 0.649 & 0.010 & $-0.002,0.023$ & 0.100 & 0.011 & $-0.001,0.023$ & 0.081 \\
\hline \multicolumn{13}{|l|}{ Infant characteristics } \\
\hline \multicolumn{13}{|l|}{ Gender } \\
\hline Male & & - & - & \multicolumn{2}{|r|}{ Reference } & & & - & - & \multicolumn{2}{|r|}{ Reference } & \\
\hline Female & & - & - & 0.140 & $0.018,0.262$ & 0.025 & & - & - & 0.002 & $-0.104,0.107$ & 0.977 \\
\hline \multicolumn{13}{|l|}{ Birth order } \\
\hline First child & & - & - & & Reference & & & - & - & & Reference & \\
\hline Not first child & & - & - & -0.229 & $-0.361,-0.096$ & 0.001 & & - & - & -0.054 & $-0.169,0.061$ & 0.360 \\
\hline BMI Z-score change at $0-15$ months & & - & - & -0.140 & $-0.187,-0.093$ & 0.001 & & - & - & 0.062 & $0.022,0.102$ & 0.003 \\
\hline
\end{tabular}

SGD, Singapore dollars.

作 early pregnancy); model 2 included the aforementioned maternal characteristics and another block of infant characteristics (infant gender, birth order and BMI $Z$-score change between 0 and 15 months). 


\section{Concern about infant's bunger}

As shown in Table 3, mothers of Indian ethnicity $(P=0.007)$, of lower educational status $(P=0 \cdot 006)$, who partially breast-fed $(P=0.004)$ and fully formula-fed $(P=0.012)$ for the first 6 months of life and who had infants with lower BMI $Z$-score change at $0-15$ months $(P=0.029)$ were generally more concerned about their infants' hunger (model 2). Maternal characteristics were stronger influences on scores of this subscale than infant correlates ( $R^{2}$ change: $\left.7 \cdot 8 \% v \cdot 0 \cdot 7 \%\right)$.

\section{Awareness of infant's bunger and satiety cues}

Mothers of Indian ethnicity $(P<0 \cdot 001)$, mothers who had male infants $(P=0 \cdot 016)$ and mothers of infants with higher BMI $Z$-score change at $0-15$ months $(P=0.024)$ were more aware of their infants' hunger and satiety cues (model 2, Table 3). Despite only one maternal correlate showing a significant association with this subscale, overall maternal characteristics still had a stronger influence on the scores of this subscale compared with infant correlates ( $R^{2}$ change: $2 \cdot 5 \%$ v. $1.8 \%$ ).

\section{Social interaction with infant during feeding}

Mothers of Indian ethnicity $(P<0.001$ for both), mothers with tertiary education $(P=0.006$ and $P=0.024)$ and mothers who were older $(P=0.003$ and $P<0.001)$ generally reported to have increased social interaction with their infants during feeding (models 1 and 2, Table 4). First-born infants $(P=0.003)$ and infants with lower BMI $Z$-score change at $0-15$ months $(P=0.048)$ were significantly associated with increased social interaction during feeding (model 2, Table 4). Maternal correlates contributed more to the variation in this subscale scores than infant correlates ( $R^{2}$ change: $6 \cdot 0 \% v .1 \cdot 4 \%$ ).

\section{Feeding infant on schedule and using food to calm infant's fussiness}

Only one characteristic from mothers and infants was associated with feeding the infant on schedule and using food to calm the infant's fussiness, respectively. Chinese mothers tended to feed an infant on schedule $(\beta=-0.436$, $95 \%$ CI $-0.619,-0.252, \quad P<0.001)$, while mothers of infants with a lower BMI $Z$-score change at $0-15$ months tended to calm infants using food when they were fussy $(\beta=-0 \cdot 069,95 \% \mathrm{CI}-0 \cdot 124,-0 \cdot 015, P=0 \cdot 013)$, after adjustment for maternal and infant characteristics (model 2, online supplementary material, Supplemental Table 2). For both of these subscales, the larger influences were attributed to maternal correlates with the $R^{2}$ change of $5.8 \%$ and $1.8 \%$, respectively, whereas the influence of infant correlates on these subscales was very minimal ( $R^{2}$ change of $<1 \%$ ).

Overall, for all of the subscales except for concern about infant's undereating or becoming underweight, maternal correlates contributed more to explaining the variances in the scores of the subscales.

\section{Discussion}

A primary purpose of the present study was to examine maternal and infant correlates of feeding beliefs and practices in a multi-ethnic Asian Singapore population. Our study has shown that ethnicity was a key maternal correlate that consistently and significantly influenced all of the examined subscales captured by the IFQ with the exception of using food to calm infant's fussiness. In addition, infant BMI change was a key infant correlate that had an influence on all of the subscales captured by the IFQ except for feeding an infant on schedule.

Similar to previously reported studies ${ }^{(14-16)}$, our cohort study suggests that there are strong cultural influences on maternal concerns over infants' weight status and adequacy of food intakes from an early age of 15 months. Congruent with other literature employing the use of the $\mathrm{IFQ}^{(23)}$ and the $\mathrm{CFQ}^{(21,32)}$, we have found that child growth was also a contributing factor to mothers' concern over infants' weight status. For example, mothers whose babies had a lower weight gain were more concerned about them undereating, while children with high BMI or overweight were positively associated with mothers showing more concern about their child being overweight.

Mothers of girls and first-born infants exhibited more concern over the infant becoming underweight and undereating. This may be related to mothers perceiving that fatter girls are 'healthier' ${ }^{\text {(33) }}$ and that girls tend to show less appetite than boys ${ }^{(34)}$. A recent study also showed that having a first-born child had a non-significant positive trend with mothers' concern about the child undereating ${ }^{(24)}$.

In the aspect of maternal concern over infant hunger (as reflected by adding cereal into an infant's bottle) and awareness of infants' hunger and satiety cues, maternal characteristics exerted greater influence than infant characteristics. Indian mothers scored higher in both aspects compared with Chinese mothers, possibly due to the traditional belief of feeding a child in excess to benefit their growth and increase in strength ${ }^{(35)}$. Similar to other studies $^{(36,37)}$, we found that mothers who received lower education and were less likely to breast-feed were more likely to add cereal to the bottle.

A larger change in infant body size reduced mothers' concern about the infant's hunger but increased mothers' awareness of infant's hunger and satiety cues. These findings were not observed by two previous studies ${ }^{(23,24)}$. However, our study points out that if a child was growing larger in body size, our mothers would be less likely to add cereal into their bottles and but would be more aware of their infant's nutritional intake. Interestingly, mothers of male infants were also more aware of their child's hunger and satiety cues, suggesting the possibility of larger appetite in boys ${ }^{(34)}$. 
Table 3 Maternal and infant characteristics associated with maternal concern about infant's hunger and awareness of infant's hunger and satiety cues; GUSTO (Growing Up in Singapore Towards healthy Outcomes) mother-offspring birth cohort, Singapore

\begin{tabular}{|c|c|c|c|c|c|c|c|c|c|c|c|c|}
\hline & \multicolumn{6}{|c|}{$\begin{array}{l}\text { Subscale: Concern about infant's } \\
\text { hunger }(n 788)\end{array}$} & \multicolumn{6}{|c|}{$\begin{array}{l}\text { Subscale: Awareness of infant's hunger and } \\
\text { satiety cues ( } n \text { 801) }\end{array}$} \\
\hline & & Model 1 & $P$ value & & Model 2 & $P$ value & & Model 1 & $P$ value & & Model 2 & $P$ value \\
\hline \multicolumn{13}{|l|}{ Maternal characteristics } \\
\hline \multicolumn{13}{|l|}{ Ethnicity } \\
\hline Chinese & \multicolumn{2}{|r|}{ Reference } & \multicolumn{4}{|c|}{ Reference } & \multicolumn{2}{|r|}{ Reference } & \multicolumn{4}{|c|}{ Reference } \\
\hline Malay & -0.126 & $-0.342,0.089$ & 0.250 & -0.109 & $-0.326,0.107$ & 0.321 & 0.071 & $-0.052,0.194$ & 0.256 & 0.051 & $-0.071,0.173$ & 0.412 \\
\hline Indian & 0.298 & $0.070,0.525$ & 0.010 & 0.316 & $0.087,0.545$ & 0.007 & 0.261 & $0.132,0.390$ & $<0.001$ & 0.233 & $0.104,0.362$ & $<0.001$ \\
\hline \multicolumn{13}{|l|}{ Education } \\
\hline None/primary/secondary & \multicolumn{2}{|r|}{ Reference } & \multicolumn{4}{|c|}{ Reference } & \multicolumn{2}{|c|}{ Reference } & \multicolumn{4}{|c|}{ Reference } \\
\hline Post-secondary & -0.091 & $-0.294,0.112$ & 0.381 & -0.079 & $-0.285,0.126$ & 0.449 & -0.016 & $-0.132,0.100$ & 0.784 & -0.010 & $-0.126,0.107$ & 0.871 \\
\hline Tertiary & -0.368 & $-0.613,-0.123$ & 0.003 & -0.352 & $-0.601,-0.103$ & 0.006 & -0.110 & $-0.249,0.029$ & 0.120 & -0.088 & $-0.229,0.052$ & 0.217 \\
\hline \multicolumn{13}{|l|}{ Household income } \\
\hline SGD0-1999 & \multicolumn{2}{|r|}{ Reference } & \multicolumn{4}{|c|}{ Reference } & \multicolumn{2}{|r|}{ Reference } & \multicolumn{4}{|c|}{ Reference } \\
\hline SGD2000-5999 & -0.213 & $-0.454,0.028$ & 0.083 & -0.200 & $-0.442,0.041$ & 0.104 & -0.065 & -0.2020 .072 & 0.354 & -0.071 & $-0.207,0.066$ & 0.309 \\
\hline \multirow{2}{*}{\multicolumn{13}{|c|}{ Milk feeding practices up to 6 months $-0.000-0.004,-0.005$}} \\
\hline & & & & & & & & & & & & \\
\hline Fully breast-fed & \multicolumn{2}{|r|}{ Reference } & \multicolumn{4}{|c|}{ Reference } & \multicolumn{2}{|c|}{ Reference } & \multicolumn{4}{|c|}{ Reference } \\
\hline Partially breast-fed & 0.398 & $0.143,0.652$ & 0.002 & 0.378 & $0.122,0.633$ & 0.004 & 0.011 & $-0.132,0.154$ & 0.885 & 0.022 & $-0.120,0.165$ & 0.758 \\
\hline Fully formula-fed & 0.432 & $0.095,0.769$ & 0.012 & 0.431 & $0.094,0.768$ & 0.012 & 0.034 & $-0.156,0.224$ & 0.724 & 0.0443 & $-0.145,0.233$ & 0.646 \\
\hline Age (years) & -0.013 & $-0.030,0.003$ & 0.104 & -0.013 & $-0.030,0.004$ & 0.145 & 0.001 & $-0.008,0.010$ & 0.821 & -0.002 & $-0.012,0.008$ & 0.707 \\
\hline Pregnancy BMI at $<15$ weeks $\left(\mathrm{kg} / \mathrm{m}^{2}\right)$ & 0.007 & $-0.011,0.025$ & 0.466 & 0.006 & $-0.012,0.024$ & 0.496 & -0.007 & $-0.017,0.003$ & 0.173 & -0.006 & $-0.017,0.004$ & 0.217 \\
\hline \multicolumn{13}{|l|}{ Infant characteristics } \\
\hline \multicolumn{13}{|l|}{ Gender } \\
\hline Male & & - & - & \multicolumn{2}{|r|}{ Reference } & & & - & - & \multicolumn{2}{|c|}{ Reference } & \\
\hline Female & & - & - & -0.078 & $-0.233,0.077$ & 0.323 & & - & - & $-0 \cdot 108$ & $-0.196,-0.020$ & 0.016 \\
\hline \multicolumn{13}{|l|}{ Birth order } \\
\hline First child & & - & - & & Reference & & & - & - & & Reference & \\
\hline Not first child & & - & - & -0.023 & $-0.191,0.146$ & 0.792 & & - & - & 0.094 & $-0.002,0.190$ & 0.073 \\
\hline BMI $Z$-score change at $0-15$ months & & - & - & -0.067 & $-0.127,0.007$ & 0.029 & & - & - & 0.039 & $0.005,0.073$ & 0.024 \\
\hline
\end{tabular}

SGD, Singapore dollars.

作 $\beta$ and $95 \% \mathrm{Cl}$. Model 1 included maternal characteristics as one block (maternal age, ethnicity, education, household monthly income, milk feeding practices in the first 6 months of life and BMI in early pregnancy); model 2 included the aforementioned maternal characteristics and another block of infant characteristics (infant gender, birth order and BMI Z-score change between 0 and 15 months). 
Table 4 Maternal and infant characteristics associated with social interaction with infant during feeding; GUSTO (Growing Up in Singapore Towards healthy Outcomes) mother-offspring birth cohort, Singapore

\begin{tabular}{|c|c|c|c|c|c|c|}
\hline & \multicolumn{6}{|c|}{ Subscale: Social interaction with infant during feeding $(n 790)$} \\
\hline & \multicolumn{2}{|c|}{ Model 1} & $P$ value & \multicolumn{2}{|r|}{ Model 2} & $P$ value \\
\hline \multicolumn{7}{|l|}{ Maternal characteristics } \\
\hline \multicolumn{7}{|l|}{ Ethnicity } \\
\hline Chinese & \multicolumn{2}{|c|}{ Reference } & \multicolumn{4}{|c|}{ Reference } \\
\hline Malay & 0.143 & $-0.037,0.323$ & 0.119 & 0.166 & $-0.013,0.346$ & 0.070 \\
\hline Indian & 0.444 & $0.254,0.633$ & $<0.001$ & 0.490 & $0.300,0.681$ & $<0.001$ \\
\hline \multicolumn{7}{|l|}{ Education } \\
\hline None/primary/secondary & \multicolumn{2}{|c|}{ Reference } & \multicolumn{4}{|c|}{ Reference } \\
\hline Post-secondary & 0.090 & $-0.081,0.261$ & 0.301 & 0.063 & $-0.109,0.235$ & 0.475 \\
\hline Tertiary & 0.285 & $0.080,0.489$ & 0.006 & 0.238 & $0.031,0.446$ & 0.024 \\
\hline \multicolumn{7}{|l|}{ Household income } \\
\hline SGD0-1999 & \multicolumn{2}{|c|}{ Reference } & \multicolumn{4}{|c|}{ Reference } \\
\hline SGD2000-5999 & 0.091 & $-0.111,0.292$ & 0.377 & 0.095 & $-0.105,0.296$ & 0.351 \\
\hline$\geq S G D 6000$ & 0.007 & $-0.245,0.259$ & 0.958 & 0.007 & $-0.245,0.258$ & 0.959 \\
\hline \multicolumn{7}{|l|}{ Milk feeding practices up to 6 months } \\
\hline Fully breast-fed & \multicolumn{2}{|c|}{ Reference } & \multicolumn{4}{|c|}{ Reference } \\
\hline Partially breast-fed & $-0 \cdot 152$ & $-0.366,0.062$ & 0.164 & -0.185 & $-0.399,0.029$ & 0.091 \\
\hline Full formula-fed & -0.191 & $-0.473,0.091$ & 0.183 & -0.214 & $-0.495,0.067$ & 0.135 \\
\hline Age (years) & 0.021 & $0.007,0.034$ & 0.003 & 0.027 & $0.013,0.042$ & $<0.001$ \\
\hline Pregnancy BMI at $<15$ weeks $\left(\mathrm{kg} / \mathrm{m}^{2}\right)$ & 0.001 & $-0.014,0.016$ & 0.915 & 0.001 & $-0.014,0.015$ & 0.943 \\
\hline \multicolumn{7}{|l|}{ Infant characteristics } \\
\hline \multicolumn{7}{|l|}{ Gender } \\
\hline Male & & - & - & \multicolumn{2}{|c|}{ Reference } & \\
\hline Female & & - & - & 0.006 & $-0.124,0.135$ & 0.933 \\
\hline \multicolumn{7}{|l|}{ Birth order } \\
\hline First child & & - & - & \multicolumn{2}{|c|}{ Reference } & \\
\hline Not first child & & - & - & -0.211 & $-0.352,-0.071$ & 0.003 \\
\hline BMI Z-score change at 0-15 months & & - & - & -0.050 & $-0.101,0.000$ & 0.048 \\
\hline
\end{tabular}

SGD, Singapore dollars.

Data are presented as $\beta$ and $95 \% \mathrm{Cl}$. Model 1 included maternal characteristics as one block (maternal age, ethnicity, education, household monthly income, milk feeding practices in the first 6 months of life and BMI in early pregnancy); model 2 included the aforementioned maternal characteristics and another block of infant characteristics (infant gender, birth order and BMI Z-score change between 0 and 15 months)

Unengaged feeding practices that lack warmth and care may negatively affect a child's ability to learn selfregulation of eating ${ }^{(38)}$. In our study, Indian ethnicity, older maternal age and higher maternal educational level were associated with increased social interaction with infants during feeding. Similar maternal correlates were also reported by Hughes et al. ${ }^{(39)}$ and Vereecken et al. ${ }^{(40)}$. We found that mothers devoted more time to social interaction during feeding when the child was the only child or the oldest child in the family. This was also the case if the child had a lower body size change, suggesting the mothers might be attempting to encourage their child to eat more in order to promote an increase in weight.

We found that the key maternal correlate to feeding an infant more on a schedule was ethnicity. This particular feeding practice has been linked to mothers who are more likely to monitor their infant's intake ${ }^{(30)}$ but are less aware of their child's hunger cues and satiety ${ }^{(31)}$. The influence of culture/ethnicity has not been previously reported; other studies have found that overweight mothers ${ }^{(41)}$ and mothers who mixed fed or fully formula-fed tended to control feeding through scheduled feeding ${ }^{(24)}$. Interestingly, in our study, the use of food to calm an infant's fussiness was associated only with a smaller change in infant body size. Unlike previous studies which have reported significant associations of this subscale with maternal correlates including ethnicity, education, income, milk feeding mode and weight status ${ }^{(8,10,23,24,41)}$, we did not find this subscale to be correlated to any maternal characteristics. A possible reason for this difference could be the younger age group of infants in our study compared with the other studies, which had older children aged 3 years and beyond ${ }^{(8,10,41)}$.

\section{Strengths and limitations}

The present study contained a relatively large sample size of a multi-ethnic population, thus providing a chance to assess ethnic influence within a socio-economic context. We used a validated and appropriate tool, namely the IFQ, to capture maternal feeding beliefs and practices during infancy. Furthermore, data on mothers and infants were collected prospectively, thus reducing the possible reverse causations in our analysis. Nevertheless, we acknowledge certain limitations of the study. We noted that there was a difference in the profiles of the responders and nonresponders to the IFQ, and thus the generalizability of our results to the younger, non-Chinese, lower household income and educational status, and in single/divorced mothers is unclear. Second, this maternal self-report questionnaire captures retrospective feeding practices ${ }^{(23)}$ 
and can be subjective ${ }^{(42)}$; also the subscales have not been validated against observed maternal feeding practices. Lastly, there may be other maternal and infant correlates or residual confounding factors, such as maternal psychosocial factors and infant temperament, which were not analysed in the present study but could contribute to the variations in the scores of the subscales. Further studies in this area with larger sample size are warranted.

\section{Conclusions}

The present study generated three significant findings. First, parents from different ethnic backgrounds may differ in their perception of the ideal weight status of their child and the appropriate amount of food their child should consume. Second, a child's weight change or change in body size significantly influences mothers' concerns over their child's weight and the way mothers choose to feed their children. Third, for most subscales, we found that maternal correlates had greater influences on maternal feeding practices and beliefs than infant correlates. The exception is maternal concern about infant's undereating or becoming underweight subscale, where infant correlates played a more significant role. These are important considerations when planning education programmes for caregivers on feeding practices. Future studies will need to consider both maternal and infant correlates when assessing determinants of maternal beliefs and practices, child eating behaviour and weight gain. Furthermore, the next steps would be to validate these feeding beliefs and practices with observed maternal feeding practices and to assess the risk to childhood overweight longitudinally. It is possible that the current observed associations may differ as the child ages and as feeding styles transit from being parent responsive to child responsive as older toddlers are more likely to dictate feeding.

\section{Acknowledgements}

Acknowledgements: This study acknowledges the contribution of the rest of the GUSTO Study Group, which includes the following: Pratibha Agarwal, Arijit Biswas, Choon Looi Bong, Birit FP Broekman, Shirong Cai, Jerry Kok Yen Chan, Yiong Huak Chan, Cornelia Yin Ing Chee, Helen Y.H. Chen, Audrey Chia, Amutha Chinnadurai, Chai Kiat Chng, Shang Chee Chong, Mei Chien Chua, Chun Ming Ding, Eric Andrew Finkelstein, Doris Fok, Marielle V. Fortier, Anne Eng Neo Goh, Yam Thiam Daniel Goh, Joshua J. Gooley, Wee Meng Han, Mark Hanson, Christiani Jeyakumar Henry, Joanna D. Holbrook, Chin-Ying Hsu, Hazel Inskip, Jeevesh Kapur, Kenneth Kwek, Ivy Yee-Man Lau, Bee Wah Lee, Yung Seng Lee, Ngee Lek, Sok Bee Lim, Yen-Ling Low, Iliana Magiati, Lourdes Mary Daniel, Michael Meaney, Cheryl Ngo, Krishnamoorthy Naiduvaje,
Wei Wei Pang, Anqi Qiu, Boon Long Quah, Victor Samuel Rajadurai, Mary Rauff, Salome A. Rebello, Jenny L. Richmond, Anne Rifkin-Graboi, Lynette Pei-Chi Shek, Allan Sheppard, Borys Shuter, Leher Singh, Shu-E Soh, Walter Stunkel, Lin Lin Su, Kok Hian Tan, Oon Hoe Teoh, Mya Thway Tint, Hugo P.S. van Bever, Rob M. van Dam, Inez Bik Yun Wong, P.C. Wong and George Seow Heong Yeo. Financial support: This research was supported by the Singapore National Research Foundation under its Translational and Clinical Research (TCR) Flagship Programme and administered by the Singapore Ministry of Health's National Medical Research Council (NMRC), Singapore (grant numbers NMRC/TCR/004-NUS/2008 and NMRC/TCR/012-NUHS/2014). Additional funding was provided by the Singapore Institute for Clinical Sciences, Agency for Science Technology and Research (A*STAR), Singapore. The funders had no role in the design, analysis or writing of this article. Conflict of interest: P.D.G., K.M.G. and Y.-S.C. have received reimbursement for speaking at conferences sponsored by companies selling nutritional products. These authors are part of an academic consortium that has received research funding from Abbot Nutrition, Nestec and Danone. None of the other authors report any potential conflict of interest. Authorship: All authors were involved in all parts of the study and approved the final manuscript. S.-M.S., K.M.G., P.D.G. and Y.-S.C. designed and led the GUSTO study. P.L.Q. and T.S.C. both contributed equally to the statistical analysis and writing of the manuscript. C.Y.B. and F.Y. provided intellectual contribution to the write-up of the manuscript. P.L.Q. and M.F-F.C. were responsible for finalizing the manuscript. Ethics of human subject participation: Written informed consent was collected from all participants upon recruitment. This study was granted ethical approval by the Institutional Review Boards of the respective hospitals involved (clinical trials registry: NCT01174875).

\section{Supplementary material}

To view supplementary material for this article, please visit http://dx.doi.org/10.1017/S1368980016000744

\section{References}

1. McPhie S, Skouteris H, McCabe M et al. (2011) Maternal correlates of preschool child eating behaviours and body mass index: a cross-sectional study. Int J Pediatr Obes $\mathbf{6}$, 476-480.

2. Cassells EL, Magarey AM, Daniels LA et al. (2014) The influence of maternal infant feeding practices and beliefs on the expression of food neophobia in toddlers. Appetite $\mathbf{8 2}$, $36-42$.

3. Webber L, Cooke L, Hill C et al. (2010) Associations between children's appetitive traits and maternal feeding practices. J Am Diet Assoc 110, 1718-1722.

4. Worobey J, Lopez MI \& Hoffman DJ (2009) Maternal behavior and infant weight gain in the first year. J Nutr Educ Behav 41, 169-175. 
5. Rodgers RF, Paxton SJ, Massey R et al. (2013) Maternal feeding practices predict weight gain and obesogenic eating behaviors in young children: a prospective study. Int $J$ Behav Nutr Phys Act 10, 24.

6. Kroller K \& Warschburger P (2008) Associations between maternal feeding style and food intake of children with a higher risk for overweight. Appetite 51, 166-172.

7. McPhie S, Skouteris H, Daniels L et al. (2014) Maternal correlates of maternal child feeding practices: a systematic review. Matern Child Nutr 10, 18-43.

8. Musher-Eizenman DR, de Lauzon-Guillain B, Holub SC et al. (2009) Child and parent characteristics related to parental feeding practices. A cross-cultural examination in the US and France. Appetite 52, 89-95.

9. Anderson CB, Hughes SO, Fisher JO et al. (2005) Cross-cultural equivalence of feeding beliefs and practices: the psychometric properties of the child feeding questionnaire among Blacks and Hispanics. Prev Med 41, 521-531.

10. Evans A, Seth JG, Smith S et al. (2011) Parental feeding practices and concerns related to child underweight, picky eating, and using food to calm differ according to ethnicity/ race, acculturation, and income. Matern Child Health J 15, 899-909.

11. Ystrom E, Barker M \& Vollrath ME (2012) Impact of mothers' negative affectivity, parental locus of control and child-feeding practices on dietary patterns of 3-year-old children: the MoBa Cohort Study. Matern Child Nutr 8, 103-114.

12. Blissett J \& Haycraft E (2008) Are parenting style and controlling feeding practices related? Appetite 50, 477-485.

13. Blissett J, Meyer C \& Haycraft E (2006) Maternal and paternal controlling feeding practices with male and female children. Appetite 47, 212-219.

14. Contento IR, Basch C \& Zybert P (2003) Body image, weight, and food choices of Latina women and their young children. J Nutr Educ Behav 35, 236-248.

15. Jain A, Sherman SN, Chamberlin LA et al. (2001) Why don't low-income mothers worry about their preschoolers being overweight? Pediatrics 107, 1138-1146.

16. Bruss MB, Morris JR, Dannison LL et al. (2005) Food, culture, and family: exploring the coordinated management of meaning regarding childhood obesity. Health Commun 18, 155-175.

17. Cachelin FM (2014) Impact of Asian American mothers' feeding beliefs and practices on child obesity in a diverse community sample. Asian Am J Psychol 5, 223-229.

18. Davison KK \& Birch LL (2001) Weight status, parent reaction, and self-concept in five-year-old girls. Pediatrics 107, 46-53.

19. Tripicchio GL, Keller KL, Johnson C et al. (2014) Differential maternal feeding practices, eating self-regulation, and adiposity in young twins. Pediatrics 134, e1399-e1404.

20. Doub AE, Moding KJ \& Stifter CA (2015) Infant and maternal predictors of early life feeding decisions. The timing of solid food introduction. Appetite $\mathbf{9 2}, 261-268$.

21. Brann LS \& Skinner JD (2005) More controlling childfeeding practices are found among parents of boys with an average body mass index compared with parents of boys with a high body mass index. I Am Diet Assoc 105 1411-1416.

22. Birch LL (2006) Child feeding practices and the etiology of obesity. Obesity (Silver Spring) 14, 343-344.

23. Baughcum AE, Powers SW, Johnson SB et al. (2001) Maternal feeding practices and beliefs and their relationships to overweight in early childhood. J Dev Behav Pediatr 22, 391-408.

24. Rametta E, Mallan KM, Daniels L et al. (2015) Relationships between maternal overweight prior to pregnancy, feeding mode and infant feeding beliefs and practices. J Paediatr Child Health 51, 913-919.

25. Soh SE, Tint MT, Gluckman PD et al. (2014) Cohort profile: Growing Up in Singapore Towards healthy Outcomes (GUSTO) birth cohort study. Int J Epidemiol $\mathbf{4 3}$, 1401-1409.

26. de Onis M, Garza C, Victora CG et al. (2004) The WHO Multicentre Growth Reference Study: planning, study design, and methodology. Food Nutr Bull 25, 1 Suppl., 15S-26S.

27. Bentler PM (1990) Comparative fit indexes in structural models. Psychol Bull 107, 238-246.

28. Bentler PM (1992) On the fit of models to covariances and methodology to the Bulletin. Psychol Bull 112, 400-404.

29. Steiger JH (1990) Structural model evaluation and modification: an interval estimation approach. Multivariate Behav Res 25, 173-180.

30. De Bourdeaudhuij I \& Sallis J (2002) Relative contribution of psychosocial variables to the explanation of physical activity in three population-based adult samples. Prev Med 34, 279-288.

31. Goldenberg RL \& Culhane JF (2005) Prepregnancy health status and the risk of preterm delivery. Arch Pediatr Adolesc Med 159, 89-90.

32. Spruijt-Metz D, Lindquist CH, Birch LL et al. (2002) Relation between mothers' child-feeding practices and children's adiposity. Am J Clin Nutr 75, 581-586.

33. Barba G, Casullo C, Russo P et al. (2008) Gender inequalities in maternal perception of healthy child body shape and their association with child body mass and blood pressure. Int J Pediatr Obes 3, 78-83.

34. Orrell-Valente JK, Hill LG, Brechwald WA et al. (2007) 'Just three more bites': an observational analysis of parents' socialization of children's eating at mealtime. Appetite $\mathbf{4 8}$, $37-45$.

35. Chandra KS, Bansal M, Nair T et al. (2014) Consensus statement on management of dyslipidemia in Indian subjects. Indian Heart J 66, Suppl. 3, S1-S51.

36. Gross RS, Mendelsohn AL, Fierman AH et al. (2014) Maternal infant feeding behaviors and disparities in early child obesity. Child Obes 10, 145-152.

37. Karp SM \& Lutenbacher M (2011) Infant feeding practices of young mothers. MCN Am J Matern Child Nurs 36, 98-103.

38. Rhee KE, Lumeng JC, Appugliese DP et al. (2006) Parenting styles and overweight status in first grade. Pediatrics 117, 2047-2054.

39. Hughes SO, Power TG, Orlet Fisher J et al. (2005) Revisiting a neglected construct: parenting styles in a child-feeding context. Appetite 44, 83-92.

40. Vereecken CA, Keukelier E \& Maes L (2004) Influence of mother's educational level on food parenting practices and food habits of young children. Appetite 43, 93-103.

41. Jingxiong J, Rosenqvist U, Huishan W et al. (2009) Relationship of parental characteristics and feeding practices to overweight in infants and young children in Beijing, China. Public Health Nutr 12, 973-978.

42. Najman JM, Williams GM, Nikles J et al. (2001) Bias influencing maternal reports of child behaviour and emotional state. Soc Psychiatry Psychiatr Epidemiol 36, 186-194. 